\title{
Intestinal absorption of cholecalciferol in alcoholic liver disease and primary biliary cirrhosis
}

\author{
J. M. BARRAGRY ${ }^{1}$, R. G. LONG, M. W. FRANCE, M. R. WILLS, \\ B. J. BOUCHER, AND SHEILA SHERLOCK \\ From the Unit of Metabolism and Endocrinology, The London Hospital Medical College, and \\ Department of Medicine, Royal Free Hospital, London
}

SUMMARY The intestinal absorption of $\left({ }^{3} \mathrm{H}\right)$ cholecalciferol was studied in five patients with alcoholic liver disease, six patients with primary biliary cirrhosis, and 15 healthy subjects. The rate of appearance in plasma of $\left({ }^{3} \mathrm{H}\right)$ cholecalciferol after oral ingestion and the subsequent appearance of $\left({ }^{3} \mathrm{H}\right)$ polar metabolites in the alcoholic subjects were similar to those in the healthy subjects. In subjects with primary biliary cirrhosis the rate of appearance in plasma of $\left({ }^{3} \mathrm{H}\right)$ cholecalciferol was significantly reduced. The rate of appearance of labelled polar metabolites of cholecalciferol was also lower in this group, suggesting that increased removal of labelled vitamin by conversion into more polar metabolites could not account for the reduced plasma $\left({ }^{3} \mathrm{H}\right)$ cholecalciferol response. It is suggested that intestinal absorption of cholecalciferol is usually normal in alcoholic liver disease but impaired in primary biliary cirrhosis. Hepatic 25-hydroxylation is normal in alcoholic liver disease but may be defective in primary biliary cirrhosis.

Chronic liver disease is not infrequently complicated by the development of bone disease, hepatic osteodystrophy, which includes osteomalacia and osteoporosis or a combination of both. Osteomalacia typically occurs in cholestatic disorders (Atkinson et al., 1956; Kehayoglou et al., 1968; Compston and Thompson, 1977) but is occasionally observed in hepatocellular disease such as active chronic hepatitis and alcoholic liver disease (Long et al., 1978). Osteoporosis has been reported both in hepatocellular and cholestatic liver disease (Atkinson et al., 1956; Wagonfeld et al., 1976; Long et al., 1978). Malabsorption of dietary calcium occurs in cholestatic disease and to a lesser extent in chronic parenchymal liver disease, and this has been attributed to vitamin D deficiency (Kehayoglou et al., 1968; Whelton et al., 1971). 25-hydroxycholecalciferol $(25(\mathrm{OH}) \mathrm{D})$ which is formed in the liver (Ponchon et al., 1969) is the precursor of the hormonally active renal metabolite 1,25-dihydroxycholecalciferol $\left(1,25(\mathrm{OH})_{2} \mathrm{D}_{3}\right)$ (Fraser and Kodicek, 1970). Low plasma concentrations of $25(\mathrm{OH}) \mathrm{D}$ occur in a wide spectrum of chronic liver disorders, both chole-

${ }^{1}$ Address for correspondence: Dr J. M. Barragry, Department

Received for publication 1 February 1979 static and hepatocellular (Wagonfeld et al., 1976; Hepner et al., 1976; Long et al., 1976) and possible contributory factors include an impairment of intestinal absorption of vitamin D or of hepatic 25-hydroxylation, dietary deficiency of vitamin $\mathrm{D}$, and inadequate exposure to ultraviolet light. Increased urinary excretion of vitamin D metabolites may also occur (Krawitt et al., 1977), while a diminution in skin synthesis of cholecalciferol in jaundiced patients cannot be discounted.

There have been few previous studies of vitamin D absorption in patients with chronic liver disease. The experimental procedures used in some of these studies have either involved the ingestion of unphysiological amounts of cholecalciferol or $25(\mathrm{OH}) \mathrm{D}$, or have not taken the enterohepatic circulation of metabolites into account, or have had to make assumptions about the effects of differing removal rates of the vitamin from the plasma (Thompson et al., 1966; Stamp, 1974; Compston and Thompson, 1977). An alternative method of measuring vitamin $\mathbf{D}$ absorption using tracer doses of labelled cholecalciferol has recently been developed (Barragry et al., 1978). Using this technique we have studied cholecalciferol absorption in groups of patients with primary biliary cirrhosis (PBC) and alcoholic liver disease (ALD). 


\section{Methods}

\section{SUBJECTS}

Approval for these studies was obtained from the Ethical Subcommittee and informed consent was obtained from both patients and control subjects. Eleven patients (10 female and one male) were studied. Their ages ranged from 32 to 69 years. Diagnoses were based on existing clinical findings, biochemical measurements and liver biopsies (Table). Five patients had alcoholic liver disease and six had primary biliary cirrhosis, the latter staged histologically according to the method of Scheuer (1967). Four of the patients with PBC (nos. 7, 8, 10,11) were receiving vitamin $D_{2}$ supplements $100000 \mathrm{IU}$ in ethyl oleate intramuscularly once monthly. Two patients with PBC (nos. 7 and 8) were on long-term cholestyramine therapy, which was discontinued 24 hours before the investigation commenced. Patients 10 and 11 had evidence of fluid retention in the form of mild ascites. No patient had raised plasma urea or creatinine concentrations. A control group comprising six healthy males and nine females (members of staff) ranging in age from 34 to 62 years was also studied.

\section{TECHNIQUES}

Plasma 25(OH)D was measured by means of the competitive protein-binding method of Edelstein et al. (1974) with rat kidney binding protein (Haddad and Chyu, 1971). The vitamin D absorption test procedure was performed using the method of Barragry et al. (1978). Subjects fasted for 12 hours before ingesting $6 \mu \mathrm{Ci}$ of $\left(1 \alpha, 2 \alpha(\mathrm{n})-{ }^{3} \mathrm{H}\right)$ Vitamin $\mathrm{D}_{3}$, specific activity $12 \cdot 3 \mathrm{Ci} / \mathrm{mmol}$ (The Radiochemical Centre) with a $30 \mathrm{~g}$ lipid breakfast. The total amount of vitamin D administered in this way was 95 IU
$(2 \cdot 4 \mu \mathrm{g})$. Venous blood samples drawn at hourly intervals for six hours were subjected to a lipid extraction procedure (Folch et al., 1957). Separation of $\left({ }^{3} \mathrm{H}\right)$ cholecalciferol from its polar metabolites (mainly 25(OH)D) was effected using silica gel column chromatography (Barragry, 1977). Radioactive counting was performed on a Nuclear Enterprises NE 8312 liquid scintillation spectrometer. The plasma content of radioactivity was calculated and expressed as a percentage of the dose of label administered assuming a plasma volume of $5 \%$ of the body weight. The conversion of $\left({ }^{3} \mathrm{H}\right)$ cholecalciferol into its more polar metabolites was calculated by expressing at each sampling time the radioactivity associated with polar metabolites of cholecalciferol as a percentage of the total (that is, the sum of plasma $\left({ }^{3} \mathrm{H}\right)$ cholecalciferol and $\left({ }^{3} \mathrm{H}\right)$ polar metabolites) plasma radioactivity at that time (polar/total, $\mathrm{P} / \mathrm{T}$ ). Plasma triglyceride concentrations were measured in the fasting state and at hourly intervals after the ingestion of the lipid meal using the method of Eggstein and Kreutz (1966).

The statistical significance of differences between the means in the groups studied was evaluated using Student's $t$ test and, where variances were nonhomogeneous or if there were gross non-normality, by use of the Mann-Whitney U test (Siegel, 1956).

\section{Results}

The Table shows the biochemical values in the two groups of patients with chronic liver disease. The mean plasma 25(OH)D level in the ALD group was $4.4 \pm \mathrm{SE} 1.6 \mathrm{ng} / \mathrm{ml}(11.0 \pm \mathrm{SE} 4.0 \mathrm{nmol} / \mathrm{l})$ and was significantly lower $(P<0.01)$ than that of the control group $(40.7 \pm \mathrm{SE} 6.6 \mathrm{ng} / \mathrm{ml}, 102 \pm \mathrm{SE} 16.5 \mathrm{nmol} / \mathrm{l})$.

Table Data from patients with chronic liver disease

\begin{tabular}{|c|c|c|c|c|c|c|c|c|}
\hline \multirow{2}{*}{$\begin{array}{l}\text { Case } \\
\text { no. }\end{array}$} & \multirow{2}{*}{$\begin{array}{l}\text { Age } \\
(y r)\end{array}$} & \multirow[t]{2}{*}{ Diagnosis } & \multicolumn{6}{|l|}{ Plasma } \\
\hline & & & $\begin{array}{l}\text { Calcium } \\
\text { mmol/l } \\
(2 \cdot 13-2 \cdot 63)\end{array}$ & $\begin{array}{l}\text { Phosphorus } \\
\text { mmol/l } \\
(0 \cdot 81-1 \cdot 45)\end{array}$ & $\begin{array}{l}\text { Alkaline } \\
\text { phosphatase } \\
\text { IU/l } \\
(20-85)\end{array}$ & $\begin{array}{l}\text { Bilirubin } \\
\text { umol/l } \\
(3-17)\end{array}$ & $\begin{array}{l}\text { Aspartate } \\
\text { transaminase } \\
I U / l \\
(<15)\end{array}$ & $\begin{array}{l}\text { Albumin } \\
\text { g/l } \\
(38-50)\end{array}$ \\
\hline \multicolumn{9}{|c|}{ Alcoholic liver disease } \\
\hline 1 & 51 & Hepatitis with cirrhosis & $2 \cdot 30$ & 0.51 & 144 & 316 & 62 & 40 \\
\hline 3 & 47 & Hepatitis with cirrhosis & $2 \cdot 60$ & $1 \cdot 22$ & 20 & 14 & 30 & 46 \\
\hline 4 & 56 & Hepatitis with fibrosis & $2 \cdot 35$ & 0.75 & 108 & 37 & 90 & 47 \\
\hline 5 & 32 & Fatty liver & 2.53 & 0.64 & 54 & 131 & 100 & 42 \\
\hline \multicolumn{9}{|c|}{ Primary biliary cirrhosis } \\
\hline 6 & 46 & Stage II & $2 \cdot 54$ & 1.07 & 228 & 13 & 37 & 45 \\
\hline 7 & 40 & Stage III & $2 \cdot 78$ & 0.56 & 490 & 331 & 84 & 46 \\
\hline 8 & 50 & Stage III & 2.46 & 0.97 & 800 & 209 & 110 & 40 \\
\hline 9 & 52 & Stage IV & $2 \cdot 30$ & 0.80 & 456 & 379 & 80 & 40 \\
\hline 10 & 69 & Stage IV & 2.06 & 0.87 & 186 & 266 & 37 & 22 \\
\hline
\end{tabular}

Normal ranges are shown in parentheses. 
Most of the subjects with $\mathrm{PBC}$ were receiving vitamin $\mathrm{D}$ supplements and, while the mean plasma $25(\mathrm{OH}) \mathrm{D}$ value, $19 \cdot 7 \pm \mathrm{SE} 14.5 \mathrm{ng} / \mathrm{ml}(49 \cdot 3 \pm$ $\mathrm{SE} 36 \cdot 2 \mathrm{nmol} / \mathrm{l})$, was lower than that of the control group, the groups were not significantly different $(P>0.05)$. The differences between the plasma 25(OH)D levels in the ALD and PBC groups were not significant $(P>0.05)$.

\section{PLASMA $\left({ }^{3} \mathrm{H}\right)$ CHOLECALCIFEROL RESPONSE}

(Fig. 1)

After the oral administration of $\left({ }^{3} \mathrm{H}\right)$ cholecalciferol the plasma $\left({ }^{3} \mathrm{H}\right)$ cholecalciferol values in the ALD group were somewhat lower than the control group, reaching six-hour levels of $9.1 \pm \operatorname{SE~} 1.5 \%$ and $12.3 \pm \mathrm{SE} 1.0 \%$ respectively of the dose of label administered. However, the differences between the groups were not significant $(P>0.05)$. In subjects with PBC the plasma $\left({ }^{3} \mathrm{H}\right)$ cholecalciferol response was substantially lower than in the control group with a mean six-hour value of $4.6 \pm$ SE $1.6 \%$. The differences between the means of these two groups were significant at four, five $(P<0.05)$, and six hours $(P<0.01)$. Two of the lowest responses observed occurred in the patients on cholestyramine therapy. The $\left({ }^{3} \mathrm{H}\right)$ cholecalciferol response in the PBC group was not significantly different from the ALD group $(P>0.05)$.

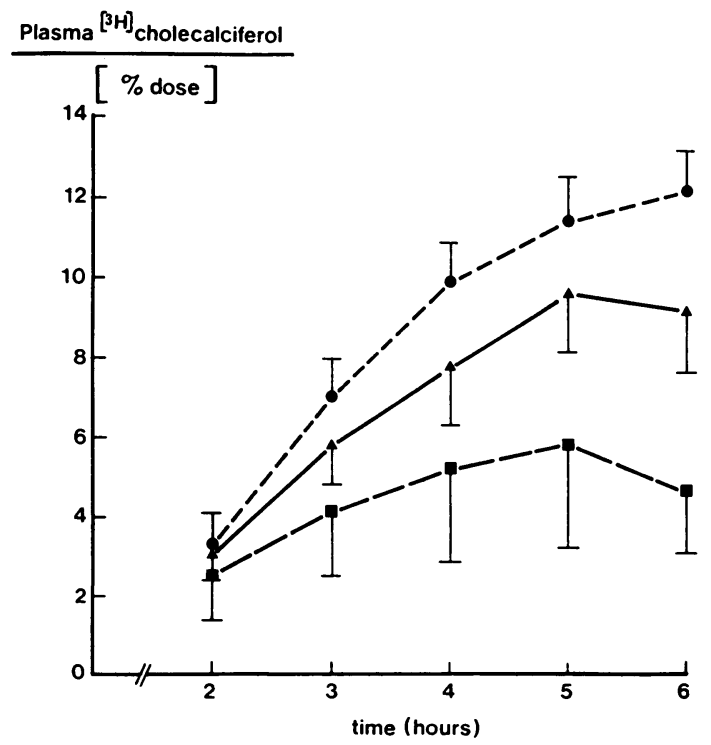

Fig. 1 Appearance of $\left({ }^{3} \mathrm{H}\right)$ cholecalciferol in plasma after an oral dose in control (O), $A L D(\triangle)$ and $P B C$ (ロ) subjects. (Mean \pm SEM).
Plasma $\left({ }^{3} \mathrm{H}\right)$ POLAR METABOLITE RESPONSE

(Fig. 2)

The plasma $\left({ }^{3} \mathrm{H}\right)$ polar metabolite response was similar in the ALD and control groups with six-hour values of $14.6 \pm \mathrm{SE} 2.8 \%$ and $15.9 \pm \mathrm{SE} 2.5 \%$ respectively $(P>0.05)$. In subjects with $\mathrm{PBC}$ the response was lower throughout compared with the control group, and the six-hour value was $2.5 \pm$ SE $1 \cdot 2 \%$. The differences between these groups were significant at three and four hours $(P<0.05)$ and five and six hours $(P<0.01)$. The differences between the PBC and ALD groups were significant at three hours $(P<0.05)$, four, five, and six hours $(\mathrm{P}<0.01)$.

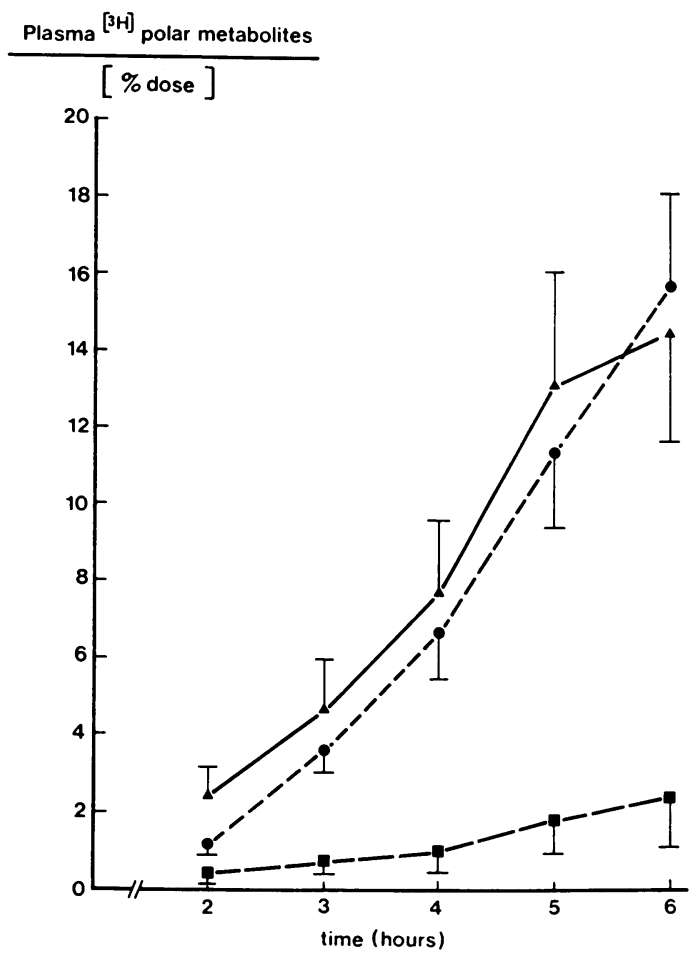

Fig. 2 Plasma $\left({ }^{3} \mathrm{H}\right)$ polar metabolite response in control $(\circlearrowleft), A L D(\triangle)$ and $P B C(\square)$ subjects. $($ Mean \pm SEM $)$.

POLAR/TOTAL PLASMA $\left({ }^{3} \mathrm{H}\right)$ RADIOACTIVITY (Fig. 3)

The polar/total $(P / T)$ values in the ALD group were somewhat greater than those of the control group but the differences were not statistically significant. The P/T values in the PBC group were lower than those of the control and ALD groups and the differences between the means of these groups were significant $(P<0.05)$ at three, four, five, and six hours. 


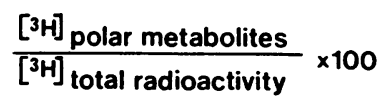

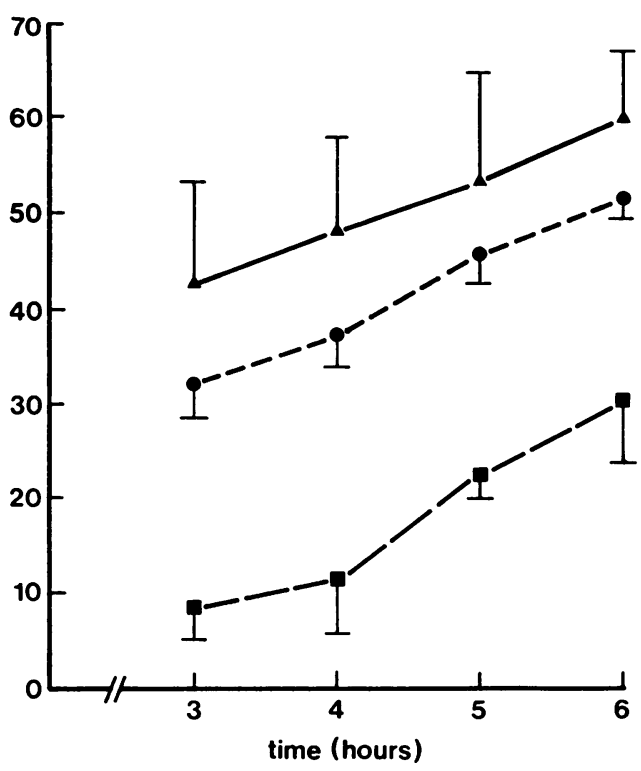

Fig. 3 Plasma $\left({ }^{3} \mathrm{H}\right)$ polar metabolite response after an oral dose of $\left({ }^{3} \mathrm{H}\right)$ cholecalciferol expressed as a percentage of total plasma $\left({ }^{3} \mathrm{H}\right)$ radioactivity in control $(\Theta)$, $A L D(\triangle)$ and PBC $(\square)$ subjects. (Mean \pm SEM).

No correlation was observed between the plasma 25(OH)D levels and the plasma $\left({ }^{3} \mathrm{H}\right)$ cholecalciferol response, $\left({ }^{3} \mathrm{H}\right)$ polar metabolite response or $\mathbf{P} / \mathbf{T}$ values.

PLASMA TRIGLYCERIDE RESPONSE (Fig. 4)

In order to establish whether an alteration in gastrointestinal motility might account for differences in $\left({ }^{3} \mathrm{H}\right)$ cholecalciferol absorption, the timing of the peak triglyceride response after the ingestion of the lipid meal was compared in all three groups. By subtracting the fasting triglyceride concentration from each hourly value the peak plasma triglyceride response was seen to occur at three hours in the control group and at five hours in the ALD group. The peak response was less well defined in the PBC group in which, after an initial rise, there was little change between two and five hours.

\section{Discussion}

The absorption test procedure used in this study measures the apparent absorption of orally administered $\left({ }^{3} \mathrm{H}\right)$ cholecalciferol and the subsequent appearance of $\left({ }^{3} \mathrm{H}\right)$ polar metabolites in the plasma. The polar/total radioactivity ratio allows the removal of absorbed labelled vitamin by hydroxylation into polar metabolites (mainly $25(\mathrm{OH}) \mathrm{D}$ ) to be taken into account. With the use of this procedure the intestinal absorption of cholecalciferol in alcoholic liver disease, which to our knowledge has not previously been defined, has been studied and found to be normal. The conversion of absorbed labelled cholecalciferol into its polar metabolites (mainly

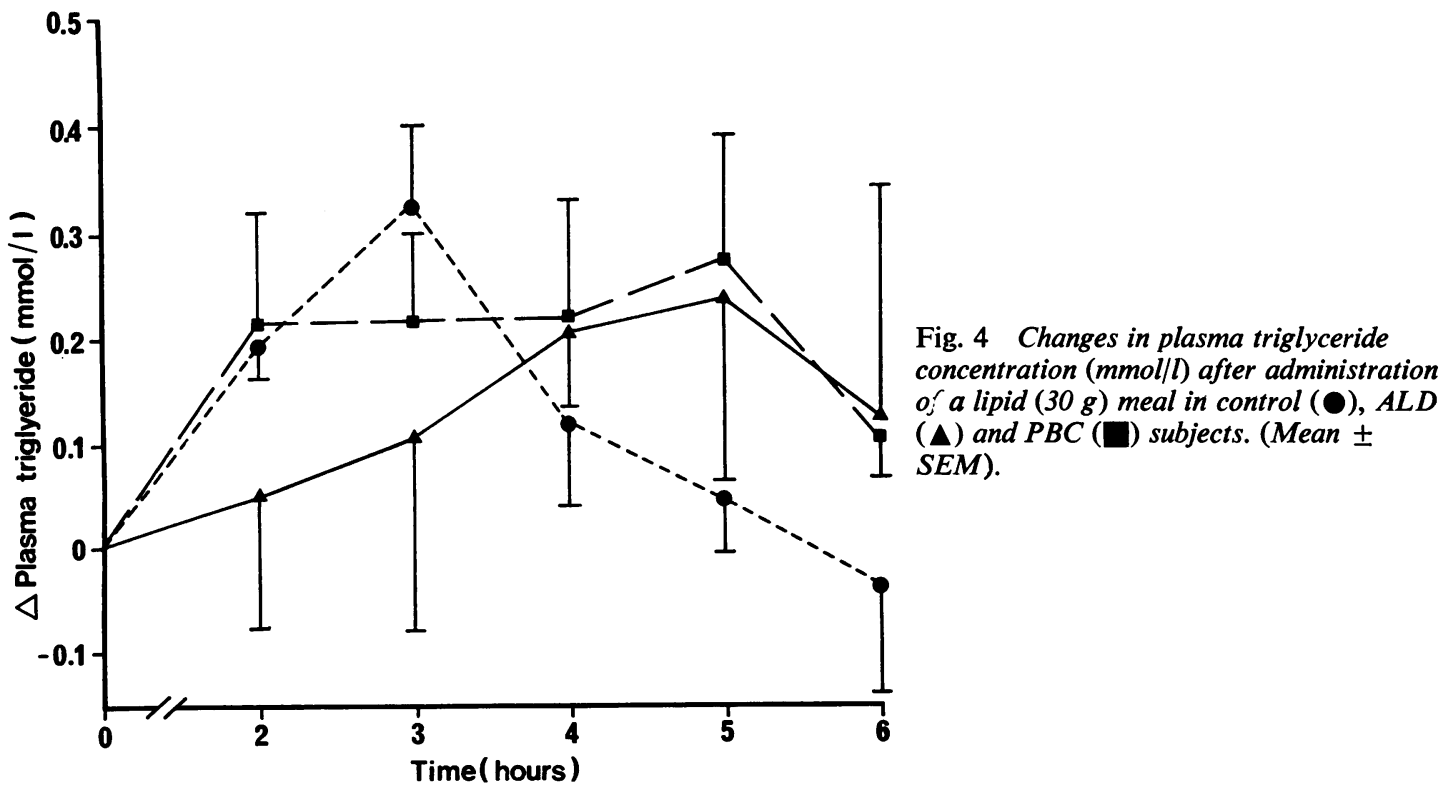


25(OH)D) was also normal and this conflicts with the recent work of Jung et al. (1978). However, in this latter study the intravenous administration of labelled vitamin in ethanol which has an 'artefactual' effect on hepatic 25-hydroxylation (Ponchon and De Luca, 1969) must be taken into account and the two studies are thus not strictly comparable. In the light of the present findings it is probable that the low plasma 25(OH)D levels observed in ALD both in this and in previous studies (Hepner et al., 1976; Long et al., 1976), and possibly the susceptibility of such patients to osteomalacia, may reflect a dietary deficiency of vitamin $\mathbf{D}$ or inadequate exposure to sunlight, or perhaps enzyme induction with formation of metabolites other than the hormonally active $1,25(\mathrm{OH})_{2} \mathrm{D}_{3}$ (Long and Wills, 1978).

After oral administration of $\left({ }^{3} \mathrm{H}\right)$ cholecalciferol the plasma $\left({ }^{3} \mathrm{H}\right)$ cholecalciferol response was significantly lower in the PBC group than in the ALD or control groups. The peak triglyceride response in the PBC group was poorly defined compared with that in the other two groups. However, such differences as were apparent in the pattern of the triglyceride response in the PBC and ALD groups could not account for the marked difference in $\left({ }^{3} \mathrm{H}\right)$ cholecalciferol responses. These findings suggest that alterations in gastric emptying and transit time were not responsible for the observed difference in cholecalciferol absorption. It is also improbable that an enhanced rate of removal of absorbed $\left({ }^{3} \mathrm{H}\right)$ cholecalciferol by conversion into active polar metabolites could account for the reduced $\left({ }^{3} \mathrm{H}\right)$ cholecalciferol response in the PBC group: in such circumstances a comparable total level of $\left({ }^{3} \mathrm{H}\right)$ plasma radioactivity and increased $\left({ }^{3} \mathrm{H}\right)$ polar metabolite and $\mathrm{P} / \mathrm{T}$ values would be expected, whereas a different pattern is seen with lower total $\left({ }^{3} \mathrm{H}\right)$ plasma radioactivity, lower $\left({ }^{3} \mathrm{H}\right)$ polar metabolites, and $\mathrm{P} / \mathrm{T}$ values. A difference in the size of the circulating pool of stable cholecalciferol would also result in an altered plasma $\left({ }^{3} \mathrm{H}\right)$ cholecalciferol response in the PBC subjects compared with the other groups. However, although cholecalciferol levels have not been measured, it is usually assumed that they are directly related to the measured plasma 25(OH)D concentration (Krawitt et al., 1977) and hence not likely to be significantly different in the PBC group compared with the control group. For these reasons we suggest that the reduced plasma $\left({ }^{3} \mathrm{H}\right)$ cholecalciferol response in the PBC subjects is indicative of impaired absorption of the labelled vitamin. It therefore appears that vitamin D malabsorption is a major factor in the pathogenesis of the low serum $25(\mathrm{OH}) \mathrm{D}$ levels and osteomalacia seen in PBC patients. The strong association between steatorrhoea and malabsorption of vitamin $D$ in eholestatic liver disease (Thompson et al., 1966;
Krawitt et al., 1977) reflects the critical importance of adequate intraluminal bile salt concentrations for vitamin $\mathrm{D}$ absorption. It is of interest that the two subjects in this series receiving cholestyramine therapy had extremely low plasma $\left({ }^{3} \mathrm{H}\right)$ cholecalciferol responses. This compound, which binds bile salts in the intestine, interferes with cholecalciferol and 25(OH)D absorption (Thompson and Thompson, 1969; Compston and Thompson, 1977) and can cause osteomalacia in man (Heaton et al., 1972).

The reduced $\left({ }^{3} \mathrm{H}\right)$ polar metabolite response and $P / T$ values in the PBC group indicate a reduction in hepatic 25-hydroxylation of absorbed label. Despite previous supplementation with vitamin $\mathrm{D}_{2}$, the mean plasma $25(\mathrm{OH}) \mathrm{D}$ level in this group was not significantly different from the control group mean and, as indicated above, the size of the circulating pool of stable cholecalciferol is unlikely to have been substantially different in the two groups. For this reason it is improbable that the significant reduction in plasma $\left({ }^{3} \mathrm{H}\right)$ polar metabolite response and $\mathrm{P} / \mathrm{T}$ values could reflect removal of absorbed $\left({ }^{3} \mathrm{H}\right)$ cholecalciferol by means other than hepatic 25-hydroxylation (Mawer et al., 1971). Moreover, a similar reduction in $\left({ }^{3} \mathrm{H}\right)$ polar metabolite and $\mathrm{P} / \mathrm{T}$ responses was seen in two PBC subjects who had not been repleted with vitamin $D$. These findings are compatible with a defect in hepatic 25-hydroxylation of absorbed cholecalciferol and are in agreement with the conclusions of Wagonfeld et al. (1976). We infer that both malabsorption of cholecalciferol and reduced 25-hydroxylation contribute to the low plasma 25(OH)D levels in subjects with primary biliary cirrhosis.

Skinner et al. (1977) have shown that patients with PBC are capable of 25-hydroxylation of vitamin D, as they eventually attain normal plasma $25(\mathrm{OH}) \mathrm{D}$ levels while on long-term (six to 72 months) treatment with 100000 units of ergocalciferol monthly. However, after a single injection of ergocalciferol, their subjects did not show a significant increment in plasma $25(\mathrm{OH}) \mathrm{D}$ levels, unlike normal subjects or those with nutritional osteomalacia. These observations taken in conjunction with the present study suggest that there is an impairment of hepatic 25-hydroxylation of cholecalciferol in PBC which can, however, be surmounted by prolonged parenteral administration of large doses of vitamin $\mathbf{D}$.

The authors wish to acknowledge the cooperation of Professor R. D. Cohen.

\section{References}

Atkinson, M., Nordin, B. E. C., and Sherlock, S. (1956). Malabsorption and bone disease in prolonged obstructive jaundice. Quarterly Journal of Medicine, 25, 299-312. 
Barragry, J. M. (1977). Some Clinical Aspects of Vitamin D Absorption and Transport. M.D. Thesis: National University of Ireland.

Barragry, J. M., France, M. W., Corless, D., Gupta, S. P., Switala, S., Boucher, B. J., and Cohen, R. D. (1978). Intestinal cholecalciferol absorption in the elderly and in younger adults. Clinical Science and Molecular Medicine, 55, 213-220.

Compston, J. E., and Thompson, R. P. H. (1977). Intestinal absorption of 25-hydroxyvitamin $D$ and osteomalacia in primary biliary cirrhosis. Lancet, 1, 721-724.

Edelstein, S., Charman, M., Lawson, D. E. M., and Kodicek, E. (1974). Competitive protein-binding assay for 25hydroxycholecalciferol. Clinical Science and Molecular Medicine, 46, 231-240.

Eggstein, M., and Kreutz, F. H. (1966). Eine neue Bestimmung der Neutralfette im Blutserum und Gwebe. I. Prinzip, Durchfürung und Besprechung der Methode. Klinische Wochenschrift, 44, 262-273.

Folch, J., Lees, M., and Sloane-Stanley, G. H. (1957). A simple method for the isolation and purification of total lipides from animal tissues. Journal of Biological Chemistry, 226, 497-509.

Fraser, D. R., and Kodicek, E. (1970). Unique biosynthesis by kidney of a biologically active vitamin $\mathrm{D}$ metabolite. Nature, 228, 764-766.

Haddad, J. G., and Chyu, K. J. (1971). Competitive proteinbinding radio-assay for 25 -hydroxycholecalciferol. Journal of Clinical Endocrinology and Metabolism, 33, 992-995.

Heaton, K. W., Lever, J. V., and Barnard, D. (1972). Osteomalacia associated with cholestyramine therapy for postilectomy diarrhea. Gastroenterology, 62, 642-646.

Hepner, G. W., Roginsky, M., and Moo, H. F. (1976). Abnormal vitamin D metabolism in patients with cirrhosis. American Journal of Digestive Diseases, 21, 527-532.

Jung, R. T., Davie, M., Hunter, J. O., Chalmers, T. M., and Lawson, D. E. M. (1978). Abnormal vitamin D metabolism in cirrhosis. Gut, 19, 290-293.

Kehayoglou, A. K., Holdsworth, C. D., Agnew, J. E., Whelton, M. J., and Sherlock, S. (1968). Bone disease and calcium absorption in primary biliary cirrhosis with special reference to vitamin D therapy. Lancet, 1, 715-719.

Krawitt, E. L., Grundman, M. J., and Mawer, E. B. (1977). Absorption, hydroxylation and excretion of vitamin $D_{3}$ in primary biliary cirrhosis. Lancet, 2, 1246-1249.
Long, R. G., Meinhard, E., Skinner, R. K., Varghese, Z., Wills, M. R., and Sherlock, S. (1978). Clinical, biochemical, and histological studies of osteomalacia, osteoporosis, and parathyroid function in chronic liver disease. Gut, 19, 85-90.

Long, R. G., Skinner, R. K., Wills, M. R., and Sherlock, S. (1976). Serum-25-hydroxy-vitamin-D in untreated parenchymal and cholestatic liver disease. Lancet, 2, 650-652.

Long, R. G., and Wills, M. R. (1978). Hepatic osteodystrophy. British Journal of Hospital Medicine, 20, 312-321.

Mawer, E. B., Lumb, G. A., Schaefer, K., and Stanbury, S. W. (1971). The metabolism of isotopically labelled vitamin $D_{3}$ in man: the influence of the state of vitamin $D$ nutrition. Clinical Science, 40, 39-53.

Ponchon, G., and De Luca, H. F. (1969). Ethanol-induced artifacts in the metabolism of ${ }^{3} \mathrm{H}$-vitamin $\mathrm{D}_{3}$. Proceedings of the Society for Experimental Biology and Medicine, 131, 727-731.

Ponchon, G., Kennan, A. L., and De Luca, H. F. (1969). 'Activation' of vitamin D by the liver. Journal of Clinical Investigation, 48, 2032-2037.

Scheuer, P. J. (1967). Primary biliary cirrhosis. Proceedings of the Royal Society of Medicine, 60, 1257-1260.

Siegel, S. (1956). Non-parametric Statistics for the Behavioral Sciences. McGraw-Hill: New York.

Skinner, R. K., Long, R. G., Sherlock, S., and Wills, M. R. (1977). 25-hydroxylation of vitamin $D$ in primary biliary cirrhosis. Lancet, 1, 720-721.

Stamp, T. C. B. (1974). Intestinal absorption of 25-hydroxycholecalciferol. Lancet, 2, 121-123.

Thompson, G. R., Lewis, B., and Booth, C. C. (1966). Absorption of vitamin $\mathrm{D}_{3}{ }^{-3} \mathrm{H}$ in control subjects and patients with intestinal malabsorption. Journal of Clinical Investigation, 45, 94-102.

Thompson, W. G., and Thompson, G. R. (1969). Effect of cholestyramine on the absorption of vitamin $D_{3}$ and calcium. Gut, 10, 717-722.

Wagonfeld, J. B., Nemchausky, B. A., Bolt, M., Horst, J. V., Boyer, J. L., and Rosenberg, I. H. (1976). Comparison of vitamin $D$ and 25 -hydroxy-vitamin-D in the therapy of primary biliary cirrhosis. Lancet, 2, 391-394.

Whelton, M. J., Kehayoglou, A. K., Agnew, J. E., Turnberg, L. A., and Sherlock, S. (1971). ${ }^{47}$ Calcium absorption in parenchymatous and biliary liver disease. Gut, 12, 978-983. 